\title{
Selective Synthesis of the Human Drug Metabolite 5'- Hydroxypropranolol by an Evolved Self-Sufficient Peroxygenase
}

\author{
Patricia Gomez de Santos, ${ }^{\dagger}$ Marina Cañellas, ${ }^{\ddagger}$ Florian Tieves, ${ }^{\S}$ Sabry H. H. Younes, ${ }^{\S}$ \\ Patricia Molina-Espeja, ${ }^{\dagger}$ Martin Hofrichter, ${ }^{\|}$Frank Hollmann, ${ }^{\S}$ Victor Guallar, ${ }^{\ddagger}$ and Miguel Alcalde ${ }^{* \dagger}$ \\ ${ }^{\dagger}$ Department of Biocatalysis, Institute of Catalysis, CSIC, 28049 Madrid, Spain \\ ${ }^{\ddagger}$ Joint BSC-CRG-IRB Research Program in Computational Biology, Barcelona Supercomputing Center, 08034 Barcelona, Spain \\ ${ }^{\S}$ Department of Biotechnology, Delft University of Technology, van der Massweg 9, 2629HZ Delft, The Netherlands \\ "Department of Bio- and Environmental Sciences, TU Dresden, International Institute Zittau, Mark 23, 02763 Zittau, Germany
}

Supporting Information

ABSTRACT: Propranolol is a widely used beta-blocker that is metabolized by human liver P450 monooxygenases into equipotent hydroxylated human drug metabolites (HDMs). It is paramount for the pharmaceutical industry to evaluate the toxicity and activity of these metabolites, but unfortunately, their synthesis has hitherto involved the use of severe conditions, with poor reaction yields and unwanted byproducts. Unspecific peroxygenases (UPOs) catalyze the selective oxyfunctionalization of $\mathrm{C}-\mathrm{H}$ bonds, and they are of particular interest in synthetic organic chemistry. Here, we describe the engineering of UPO from Agrocybe aegerita for the efficient synthesis of $5^{\prime}$-hydroxypropranolol $\left(5^{\prime}-\mathrm{OHP}\right)$. We

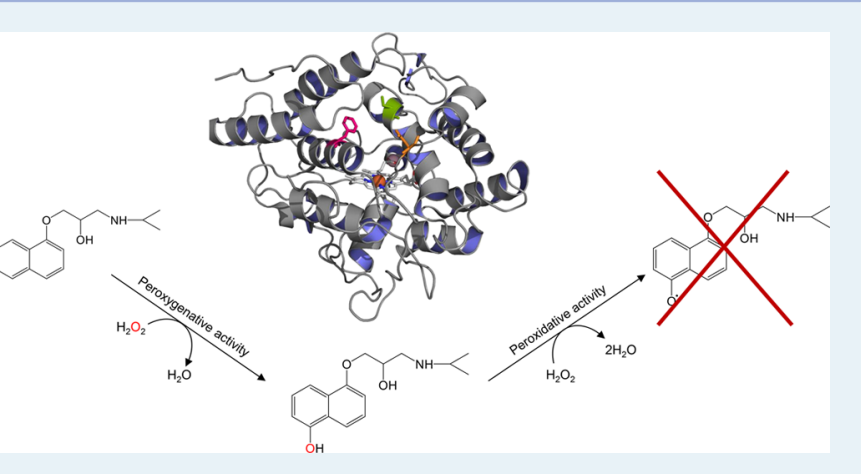
employed a structure-guided evolution approach combined with computational analysis, with the aim of avoiding unwanted phenoxyl radical coupling without having to dope the reaction with radical scavengers. The evolved biocatalyst showed a catalytic efficiency enhanced by 2 orders of magnitude and $99 \%$ regioselectivity for the synthesis of 5 '-OHP. When the UPO mutant was combined with an $\mathrm{H}_{2} \mathrm{O}_{2}$ in situ generation system using methanol as sacrificial electron donor, total turnover numbers of up to 264000 were achieved, offering a cost-effective and readily scalable method to rapidly prepare $5^{\prime}$-OHP.

KEYWORDS: unspecific peroxygenase, human drug metabolites, 5'-hydroxypropranolol, directed evolution, peroxygenative activity, peroxidative activity, in situ $\mathrm{H}_{2} \mathrm{O}_{2}$ generation system

\section{INTRODUCTION}

New drugs are currently being designed thanks to a better understanding of the biological targets associated with different diseases. As such, modern organic chemistry is becoming more and more involved in the discovery and testing of new bioactive compounds. ${ }^{1}$ The human liver is in charge of the metabolism of most drugs, principally through the catalytic action of cytochrome P450-monooxygenases (P450s). Their activities are responsible for the release of human drug metabolites (HDMs), which may be biologically active through different pharmacological, toxicological, or physiological interactions. Thus, it is important to be capable of synthesizing HDMs in order to perform adequate drug bioavailability, pharmacodynamics, and pharmacokinetics studies. ${ }^{2,3}$ Indeed, the U.S. Food and Drug Administration (FDA) guidelines for metabolites in safety testing (MIST) declare that all metabolites generated at $>10 \%$ of the total parent drug-related exposure must be subjected to safety testing. ${ }^{4}$ Among the most important HDMs are those derived from propranolol (1-naphthalen-1-yloxy-3(propan-2-ylamino)propan-2-ol), a $\beta$-blocker widely used to treat high blood pressure, to control heart rhythm, or to prevent migraines. ${ }^{5}$ The two main hydroxylated metabolites of propranolol are $5^{\prime}$-hydroxypropranolol $\left(5^{\prime}\right.$-OHP) and $4^{\prime}$ hydroxypropranolol $\left(4^{\prime}-\mathrm{OHP}\right)$ which have equipotent $\beta$ receptor antagonist activity compared to that of propranolol. ${ }^{6}$ However, their chemical synthesis is associated with poor reaction yields, an excessive number of steps and it requires high-energy input and harsh conditions, limiting their utility. ${ }^{7,8}$

The use of enzymes to hydroxylate propranolol has been studied, such as human P450s isolated from hepatic microsomes or produced in heterologous hosts, yet the constraints on expression, instability, and the low reaction rates are still serious obstacles that must be overcome. ${ }^{9}$ Human P450s are membrane bound and cofactor dependent biocatalysts, such that a simpler and more autonomous system would be desirable. Accordingly, soluble bacterial P450-BM3 was engineered to work via the "peroxide shunt" pathway, i.e., fueled by catalytic amounts of $\mathrm{H}_{2} \mathrm{O}_{2}$ in the absence of redox

Received: March 13, 2018

Revised: April 19, 2018

Published: April 19, 2018 
Scheme 1. Transformation of Propranolol by UPO in the Presence of Ascorbic Acid as a Radical Scavenger ${ }^{a}$

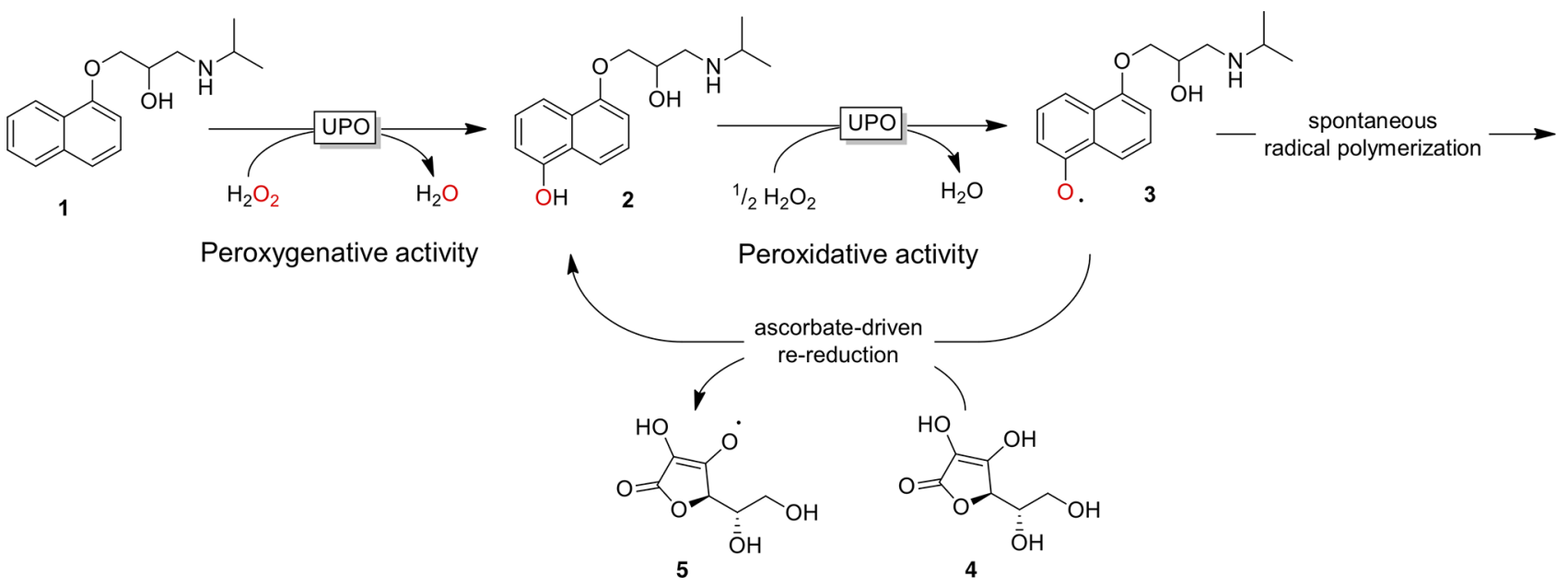

${ }^{a}$ Peroxygenative activity converts propranolol (1) into 5 -OHP (2), a substrate of the peroxidative activity of the enzyme that leads to the formation of phenoxyl radicals (3), which can in turn undergo nonenzymatic coupling and polymerization. The inclusion of ascorbic acid (4) in the reaction mixture can alleviate the formation of unwanted side-products by reducing the conversion of (3) to (2) while it is oxidized into ascorbyl radical (5).

cofactors (NADPH) and auxiliary flavoproteins, just like an "artificial" peroxygenase. In addition, an ensemble of P450peroxygenase variants was tailored to transform propranolol into a complex mixture of compounds enriched in the dealkylation product desisopropylpropranolol (DIP), along with low amounts of $4^{\prime}$-OHP and $5^{\prime}$-OHP. ${ }^{10}$ These experiments pointed the way to develop a novel approach for the synthesis of HDMs using the first, "truly natural", unspecific peroxygenase (UPO; EC 1.11.2.1), an extracellular hemethiolate enzyme with mono(per)oxygenase activity that was discovered at the beginning of this century. ${ }^{11,12}$ Unlike P450s, the major product of UPO was shown to be 5'-OHP (91\% regioselectivity), along with only minor amounts of DIP. ${ }^{13}$ Despite this promising performance, UPOs can still not be used on an industrial scale due to the coexistence of peroxygenative ( $P$; O-transferring two-electron oxidations) and peroxidative activities ( $p$; one-electron oxidation reactions) in the same biocatalyst. $^{13-15}$ Hence, the enhancement of the $P: p$ ratio is fundamental to perform $\mathrm{C}-\mathrm{H}$ oxyfunctionalization with UPO, as demonstrated in recent works. ${ }^{16,17}$ Indeed, the products of this peroxygenative activity on aromatics like propranolol become substrates of UPO's peroxidative activity, which ultimately leads to the formation of a complex mixture of phenoxyl radicals (including semiquinones) and their disproportionation (quinones) and coupling products. This mixture is further clouded by nonenzymatic polymerization, affecting the final yields and the purification of the target compounds. ${ }^{18,19}$ Such problems might be partially circumvented by doping the reaction with expensive phenoxyl radical scavengers (e.g., ascorbic acid), although this solution is far from practical in terms of developing a cost-effective strategy (Scheme 1).

In a previous study, we described the heterologous functional expression of UPO from the agaric basidiomycete Agrocybe aegerita (AaeUPO) in different yeasts via directed evolution. ${ }^{20,21}$ This evolution platform (PaDa-I, secretion mutant carrying four mutations in the signal peptide and five more in the mature protein) enabled us to perform further rounds of random mutation and screening to tailor an efficient UPO for the synthesis of 1-naphthol, notably increasing the $P: p$ ratio of the final JaWa variant (containing the G241D-R257K mutations). ${ }^{16}$ In this work, we have combined computational simulations with directed evolution methods to design a UPO variant for the high-efficient, selective synthesis of $5^{\prime}$-OHP from propranolol in the absence of radical scavengers. We first made a benchmarking with native and evolved UPOs in the transformation of propranolol, selecting JaWa variant as the most suitable departure point for engineering. Focused mutagenesis and DNA recombination in yeast was coupled to a specific high-throughput assay for the synthesis of $5^{\prime}$-OHP, yielding a final variant that was characterized biochemically in depth. To bypass the oxidative inactivation suffered by UPO and maximize the total turnover numbers (TTN), an enzymatic cascade for the in situ supply of $\mathrm{H}_{2} \mathrm{O}_{2}$ using methanol as sacrificial electron donor was coupled to the reaction. The effect of the $P: p$ ratio during the synthesis of 5 -OHP by the evolved UPO was analyzed by ligand migration and molecular dynamics simulations aimed at obtaining an atomic explanation of the mutations involved in the catalysis.

\section{RESULTS AND DISCUSSION}

As a starting point for the present study, we used a colorimetric screening assay based on 4-aminoantypirine (4-AAP) $)^{22}$ to benchmark the wildtype UPO (AaeUPO), PaDa-I, and JaWa mutants in the reaction with propranolol, assessing the variants in terms of their activity in the presence and absence of ascorbic acid (AA); see Figures S1-S3 in the Supporting Information. Significantly, the JaWa mutant outperformed both the AaeUPO and PaDa-I variants by $\sim 4$-fold (in both the presence and absence of AA; Figure S3b in the Supporting Information). Given that JaWa showed TTN of 50000 in the transformation of naphthalene into 1-naphthol, ${ }^{16}$ the structural similarities between naphthalene and propranolol, and the location of the G241D mutation at the entrance of the heme access channel, we searched for new catalytic motifs to be subjected to focused evolution. Molecular docking simulations ${ }^{23}$ with propranolol underlined the possibility that, along with Phe191, the G241D mutation favored the anchoring of propranolol (Figure 1). Accordingly, we selected the D187-V248 segment for random mutagenesis and DNA recombination by MORPHING (mutagenic organized recombination process by homologous 


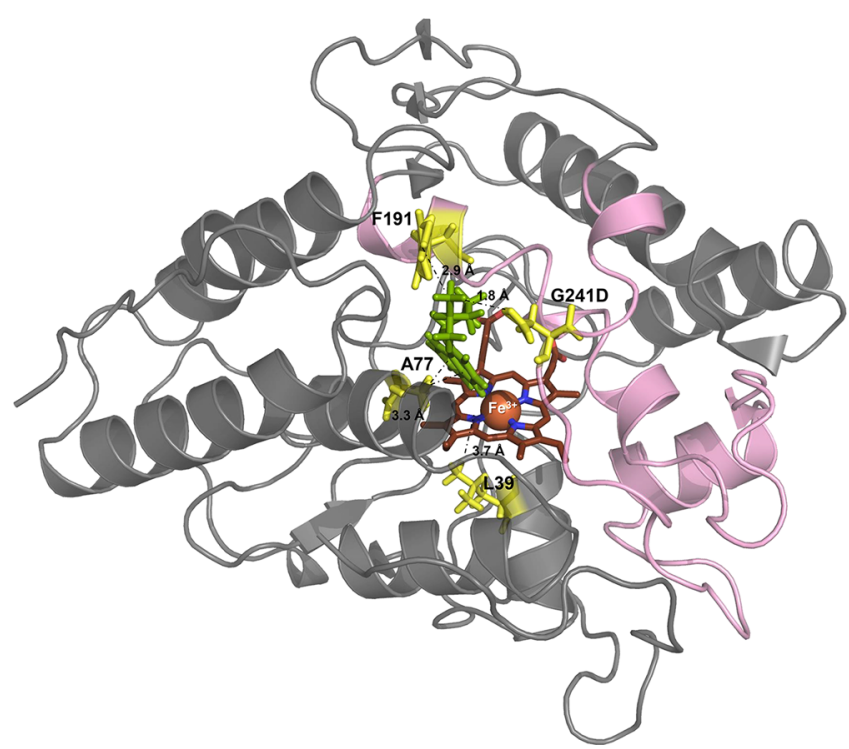

Figure 1. Selected region for focused evolution. The UPO structure (JaWa mutant) is shown as a gray cartoon, and the relevant amino acids are indicated in yellow, together with the distances between them and the propranolol molecule (in green) or to the heme group (in dark red). The F191 position and G241D substitution seem to be involved in positioning the aliphatic branch of propranolol, while A77 apparently interacts with the aromatic rings and L39 lies underneath the heme. The D187-V248 segment (in pink) was subjected to MORPHING, harboring the $\alpha$-helix where F191 is located and the loop of G241D. Docking simulations were performed using Molecular Operating Environment (MOE) software ${ }^{23}$ and the crystal structure of the evolved UPO at a resolution of $1.2 \AA$ (provided by Prof. Julia Sanz, IQFR-CSIC, Madrid, unpublished material).

in vivo grouping), ${ }^{24}$ excluding the introduction of destabilizing mutations in the remaining protein structure. We constructed two mutant libraries with different mutational loads and screened them using the 4-AAP assay (Figure S4 in the Supporting Information). As selection criterion, we imposed that UPO variants had to oxidize propranolol exceeding a threshold of 1.5 -fold of parental's activity. After two consecutive rescreenings, the six selected clones that satisfied the activity threshold carried the same single substitution (F191S), which did not jeopardize thermostability as the $T_{50}$ value for both the parental JaWa and the mutant was maintained at $\sim 60{ }^{\circ} \mathrm{C}$ (Figures S4 and S5 in the Supporting Information). This mutation improved the formation of $5^{\prime}$ OHP in the absence of AA up to $230 \%$, and most importantly, the ratio between both reactions enhanced 1.8-fold in the presence and absence of AA. Given that Phe191 and Phe76 are responsible for defining the entrance to the heme access channel, whereas the aromatic triad formed by Phe69, Phe121, and Phe199 is involved in orienting the substrate for catalysis, all these residues were studied by saturation mutagenesis using as template the F191S variant (Figure S6 in the Supporting Information). ${ }^{25}$ We first designed a combinatorial saturation mutagenesis library of Phe191 and Phe76 in which the most active clones exclusively incorporated again the F191S substitution. When individual saturation mutagenesis was performed at Phe69, Phe121, and Phe199, a set of nonfunctional libraries was obtained ( $80 \%$ inactive clones), with no further beneficial substitutions identified (Figure S7 in the Supporting Information).
The mutant clone containing the F191S mutation (named SoLo), JaWa, PaDa-I, and AaeUPO were all produced, purified to homogeneity [Reinheitszahl, $R z\left(A_{418} / A_{280}\right) \approx 2.2$ ] and characterized biochemically and computationally at the atomic level. We first analyzed the transformation of propranolol by HPLC-PDA (Figure 2c), and notably, the regioselectivity for 5 '-OHP shifted from $91 \%$ in AaeUPO to $99 \%$ in PaDa-I, JaWa and SoLo. When boosting the UPO by periodic dosing with 2 $\mathrm{mM} \mathrm{H}_{2} \mathrm{O}_{2}$ over the course of the reaction, without supplying AA, TTNs of 3000, 15000 , and 45000 were achieved for the AaeUPO, JaWa, and SoLo mutants, respectively, roughly representing a 15 -fold improvement of SoLo relative to the wildtype AaeUPO (Figure 2a,b). More significantly, in the absence of AA, the SoLo mutant still outperformed the TTN of the wildtype doped with AA more than 3-fold (viz. 45000 and 14000 TTN for SoLo in the absence of AA and AaeUPO in the presence of AA, respectively).

Kinetic parameters were measured for the one-electron oxidation of ABTS (peroxidative activity), for the two-electron oxidation of propranolol into 5'-OHP (peroxygenative activity), and for $\mathrm{H}_{2} \mathrm{O}_{2}$ with benzyl alcohol as peroxygenative substrate (Table 1). SoLo showed a striking 14-fold and 17-fold drop in the catalytic efficiency $\left(k_{\text {cat }} / K_{\mathrm{m}}\right)$ with ABTS relative to AaeUPO and $\mathrm{PaDa}$-I, respectively, while maintaining similar performance as JaWa. The strong enhancement in the $K_{\mathrm{m}}$, with a maximal 23-fold increase relative to AaeUPO was mostly responsible for this effect. Kinetic differences for propranolol were even more dramatic and the catalytic efficiencies for JaWa and SoLo were 2 orders of magnitude higher than for AaeUPO and PaDa-I, mostly due to the important 5- to 10 -fold decrease in the $K_{\mathrm{m}}$ for this substrate. The kinetics for $\mathrm{H}_{2} \mathrm{O}_{2}$ in the peroxygenation of benzyl alcohol did not differ among the UPO variants.

In order to study the differences found between the AaeUPO, PaDa-I, JaWa, and SoLo variants during propranolol hydroxylation at the atomic level, we turned to molecular modeling employing PELE (Protein Energy Landscape Exploration), a Monte Carlo algorithm capable of effectively sampling the protein-ligand conformational space. ${ }^{26}$ We first modeled propanolol diffusion to the active site for each variant, finding that binding energies and distances largely correlate with the experimental $K_{\mathrm{m}}$ (Figure 3 and Supporting Movie). To facilitate oxygenation, ideally the distances between the $C_{5}$ propranolol carbon atom and the catalytic heme-ferryl oxygen should be around (or below) $4 \AA$. JaWa, with the lowest $K_{\mathrm{m}}$ for propranolol, clearly presents the best "catalytic minimum", with a distance around $3.5 \AA$ and a binding energy at ca. $-70 \mathrm{kcal} /$ mol. On the other hand, AaeUPO and PaDa-I, with noticeably higher $K_{\mathrm{m}}$, have markedly worse binding energy profiles, which would result in the necessity of adding more substrate to reach correct catalytic positions. Moreover, when we analyzed the relative distance distribution of substrate's $\mathrm{C}_{5}$ atom in the active site (Figure 3), we obtained a similar tendency: the relative frequency of structures below $4 \AA$ is significantly higher for JaWa and SoLo variants. In addition, simulations provided important insights into the influence of the G241D mutation present in both JaWa and SoLo but absent in AaeUPO and PaDa-I (Supporting Movie), which facilitates the anchoring of the substrate in a more favorable orientation for hydroxylation. Besides, the Phe191 residue seems to tighten the stabilization of this catalytic orientation in the JaWa variant which is in agreement with the slight kinetic differences between both variants for propranolol. To obtain further structural insights into the changes caused by F191S mutation, 100 ns molecular 
A

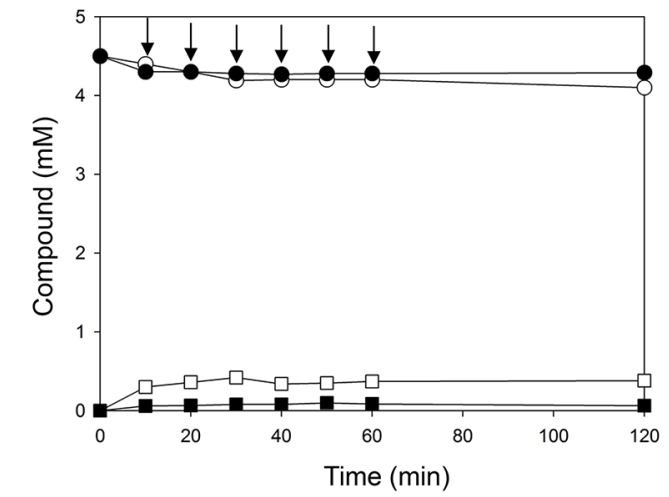

C

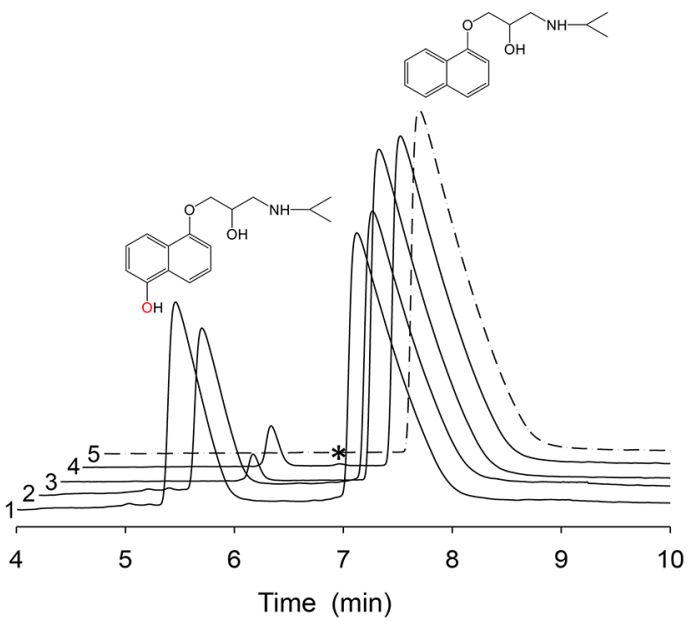

B

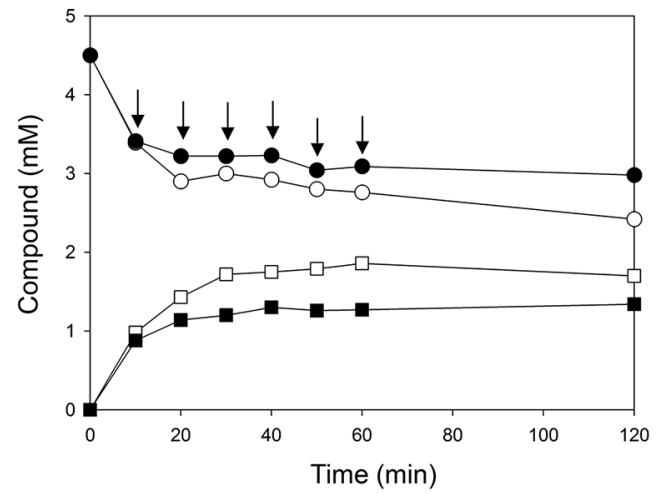

D

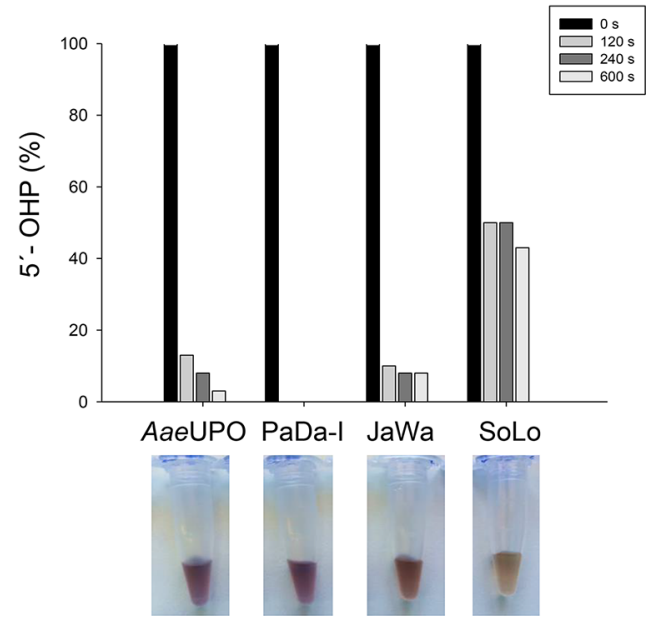

Figure 2. Propranolol conversion by native and mutant UPOs. (A and B) Time course of the reactions over $120 \mathrm{~min}$ at $\mathrm{pH} 7.0$ with the wildtype AaeUPO and the SoLo mutant, respectively. White circles, propranolol (with AA); black circles, propranolol (without AA); white squares, $5^{\prime}$-OHP (with AA); black squares, propranolol (without AA); arrows, periodic pulses of $2 \mathrm{mM} \mathrm{H}_{2} \mathrm{O}_{2}$. The total turnover numbers (TTN, $\mu$ mol product/ $\mu$ mol enzyme) were estimated from the $5^{\prime}$-OHP concentration after $120 \mathrm{~min}$. (C) The HPLC elution profiles after a reaction time of $60 \mathrm{~min}$ in the absence of AA: 1, SoLo; 2, JaWa; 3, PaDa-I; 4, AaeUPO; 5, control without enzyme; and *, traces of DIP. (D) Conversion of 5'-OHP into phenoxyl radicals and polymers. Reaction conditions can be found in the Materials and Methods section.

\section{Table 1. Steady Kinetic Parameters of UPO Variants}

\begin{tabular}{|c|c|c|c|c|c|}
\hline substrate & kinetic constant & AaeUPO & $\mathrm{PaDa}-\mathrm{I}$ & $\mathrm{JaWa}$ & SoLo \\
\hline \multirow[t]{3}{*}{ ABTS } & $K_{\mathrm{m}}(\mu \mathrm{M})$ & $25 \pm 2$ & $50 \pm 6$ & $181 \pm 22$ & $568 \pm 91$ \\
\hline & $k_{\text {cat }}\left(\mathrm{s}^{-1}\right)$ & $221 \pm 6$ & $546 \pm 19$ & $125 \pm 5$ & $365 \pm 23$ \\
\hline & $k_{\mathrm{cat}} / K_{\mathrm{m}}\left(\mathrm{M}^{-1} \mathrm{~s}^{-1}\right)$ & $8.8 \times 10^{6} \pm 6.9 \times 10^{5}$ & $11.0 \times 10^{6} \pm 6.0 \times 10^{5}$ & $6.9 \times 10^{5} \pm 6.3 \times 10^{4}$ & $6.4 \times 10^{5} \pm 6.7 \times 10^{4}$ \\
\hline \multirow[t]{3}{*}{ propranolol } & $K_{\mathrm{m}}(\mu \mathrm{M})$ & $2239 \pm 333$ & $2268 \pm 220$ & $244 \pm 92$ & $391 \pm 97$ \\
\hline & $k_{\text {cat }}\left(\mathrm{s}^{-1}\right)$ & $150 \pm 12$ & $212 \pm 11$ & $765 \pm 76$ & $497 \pm 35$ \\
\hline & $k_{\mathrm{cat}} / K_{\mathrm{m}}\left(\mathrm{M}^{-1} \mathrm{~s}^{-1}\right)$ & $6.7 \times 10^{4} \pm 4.8 \times 10^{3}$ & $9.3 \times 10^{4} \pm 4.3 \times 10^{3}$ & $3.1 \times 10^{6} \pm 0.9 \times 10^{5}$ & $1.3 \times 10^{6} \pm 0.2 \times 10^{5}$ \\
\hline \multirow[t]{3}{*}{$\mathrm{H}_{2} \mathrm{O}_{2}$} & $K_{\mathrm{m}}(\mu \mathrm{M})$ & $1370 \pm 162$ & $1530 \pm 80$ & $1250 \pm 300$ & $1430 \pm 153$ \\
\hline & $k_{\text {cat }}\left(\mathrm{s}^{-1}\right)$ & $290 \pm 15$ & $676 \pm 24$ & $447 \pm 40$ & $446 \pm 23$ \\
\hline & $k_{\mathrm{cat}} / K_{\mathrm{m}}\left(\mathrm{M}^{-1} \mathrm{~s}^{-1}\right)$ & $2.1 \times 10^{5} \pm 1.5 \times 10^{4}$ & $4.4 \times 10^{5} \pm 12.0 \times 10^{4}$ & $3.6 \times 10^{5} \pm 5.9 \times 10^{4}$ & $3.1 \times 10^{5} \pm 1.8 \times 10^{4}$ \\
\hline
\end{tabular}

dynamics (MD) were performed with JaWa and SoLo. MD pocket method $^{27}$ was used to track heme's cavity volume changes along the $\mathrm{MD}$ trajectories, showing a widening of the SoLo variant pocket compared to Jawa of $\sim 50 \AA^{3}$ (Figure $4 \mathrm{C}-$ $\mathrm{E})$. The most obvious reason behind the cavity broadening is the mutation Phe191 to a less bulky amino acid such as serine. Moreover, structure visual inspection in JaWa shows that Phe191 tends to be placed in the hydrophobic heme cavity, causing a displacement of the $\alpha$-helix hosting it and reducing the heme pocket volume. In the SoLo variant, such movement does not occur since Ser191 is kept buried into the protein by a hydrogen bond interaction within its hosting $\alpha$-helix (Figure 4A,B).

However, we still wanted to ascertain why there was more 5 OHP formed by SoLo than by JaWa, particularly given that the latter had an even higher catalytic efficiency for propranolol (Table 1). We hypothesized that the F191S mutation, which widens the access channel (Figure 4), could play an important role in bypassing the unwanted peroxidative activity on $5^{\prime}$-OHP (2) and the ensuing formation of the phenoxyl radical (3), thereby increasing the $P: p$ ratio (numbering according to Scheme 1). To unveil the weaker peroxidative activity of SoLo, we measured the disappearance of 2 by HPLC-PDA during the 

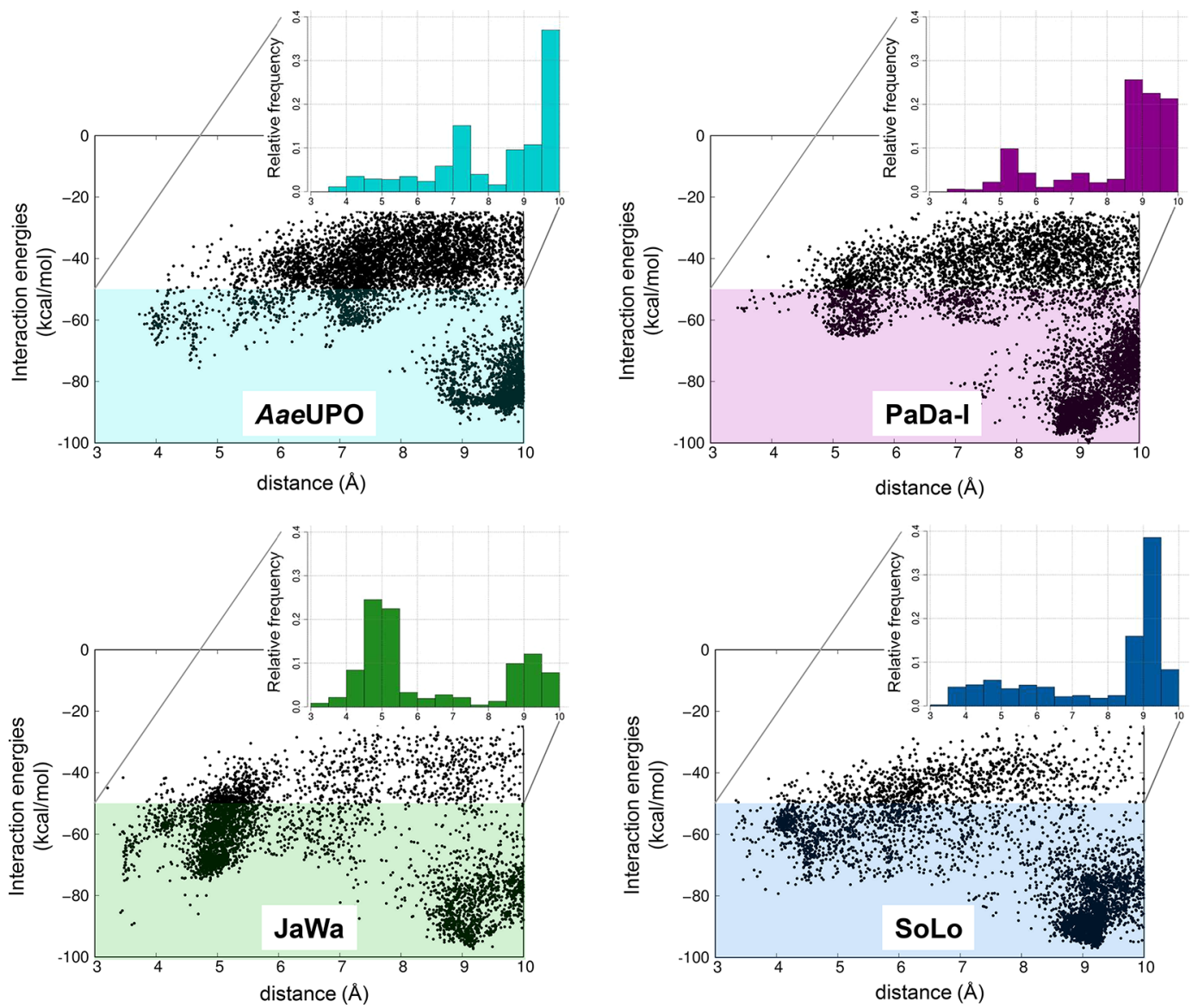

Figure 3. Computational analysis of propranolol diffusion in native and mutant UPOs. Interaction energies (in kcal-mol ${ }^{-1}$ ) vs ligand distances (in $\AA$ ) from PELE simulations with propranolol in AaeUPO, PaDa-I, JaWa, and SoLo UPO variants. The distances are between the reactive O atom in the heme compound $\mathrm{I}$ and the $\mathrm{C}_{5}$ atom of propranolol. The top-right (inset) plots show the relative population for all of the structures with interaction energies below $-50 \mathrm{kcal} \mathrm{mol}^{-1}$ using binning widths of $0.5 \AA$.

Scheme 2. Enzymatic Cascade for in Situ $\mathrm{H}_{2} \mathrm{O}_{2}$ Generation ${ }^{a}$

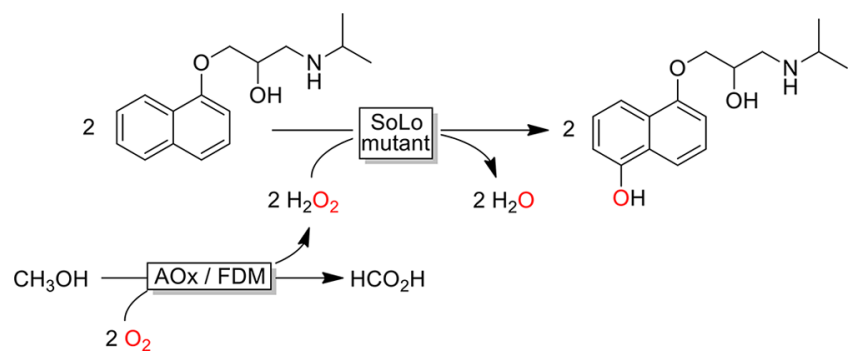

${ }^{a}$ Alcohol oxidase (AOx) and formaldehyde dismutase (FDM) perform the double oxidation of methanol to formic acid for the generation of two equivalents of $\mathrm{H}_{2} \mathrm{O}_{2}{ }^{28}$ which are used by the UPO mutant (SoLo) for the formation of $5^{\prime}$-OHP.

reaction with the different variants in the absence of AA (4), using $\mathbf{2}$ as the departure reducing substrate. Pleasingly, the rate of converting 2 into 3 was noteworthy for all of the variants except SoLo, which maintained a concentration of the substrate 10-fold higher than that of the rest of the variants after $10 \mathrm{~min}$ of the reaction (Figure 2d). These noticeable differences became readily visible because the polymeric products formed through the nonenzymatic coupling of the phenoxyl radicals are colored (see inset in Figure 2d). These results were confirmed computationally by PELE whereby the 5'-OHP diffusion addressed the significantly smaller concentration of this peroxidative substrate at lower distances $(<5 \AA)$ from the heme catalytic center in SoLo compared to JaWa, as well as shorter residence times in the binding site (Figure S8 in the Supporting Information) which results in the inefficient $5^{\prime}$ OHP oxidation by SoLo variant. Taken together, our results unequivocally show that, while the F191S mutation acts as the main driver of the remarkable decrease in peroxidative activity on 2 , the G241D change is mostly responsible for the improved peroxygenative activity on 1 (Figure S9 in the Supporting Information).

To address the well-known lability of heme-containing enzymes (including UPOs) against $\mathrm{H}_{2} \mathrm{O}_{2}$, we evaluated two strategies using either in situ generation of $\mathrm{H}_{2} \mathrm{O}_{2}$ from ambient $\mathrm{O}_{2}{ }^{28}$ or using tert-butyl hydroperoxide (tert-BuOOH) as milder peroxide source. ${ }^{29}$ For in situ $\mathrm{H}_{2} \mathrm{O}_{2}$ generation we utilized a bienzymatic cascade comprising alcohol oxidase ( $\mathrm{AOx}$ ) and formaldehyde dismutase (FDM) for the double oxidation of methanol to formic acid (generating two equivalents of $\mathrm{H}_{2} \mathrm{O}_{2}$, Scheme 2). ${ }^{28}$ With such a system, TTNs as high as 264000 and 226000 were achieved with and without AA, respectively. Also the second strategy, i.e., using tert- $\mathrm{BuOOH}$ as a milder oxidant, proved successful (Figure S10 in the Supporting Information). On a semipreparative scale, 20 and $10 \mathrm{mM}$ of 5 -OHP were produced (20 and $40 \%$ analytical yield, respectively) with and without AA, respectively. The final product was isolated and further purified via a one-step flash chromatography step yielding $10.5 \mathrm{mg}$ of pure $5^{\prime}-\mathrm{OHP}$ (as confirmed by ${ }^{1} \mathrm{H} \mathrm{NMR}$, 

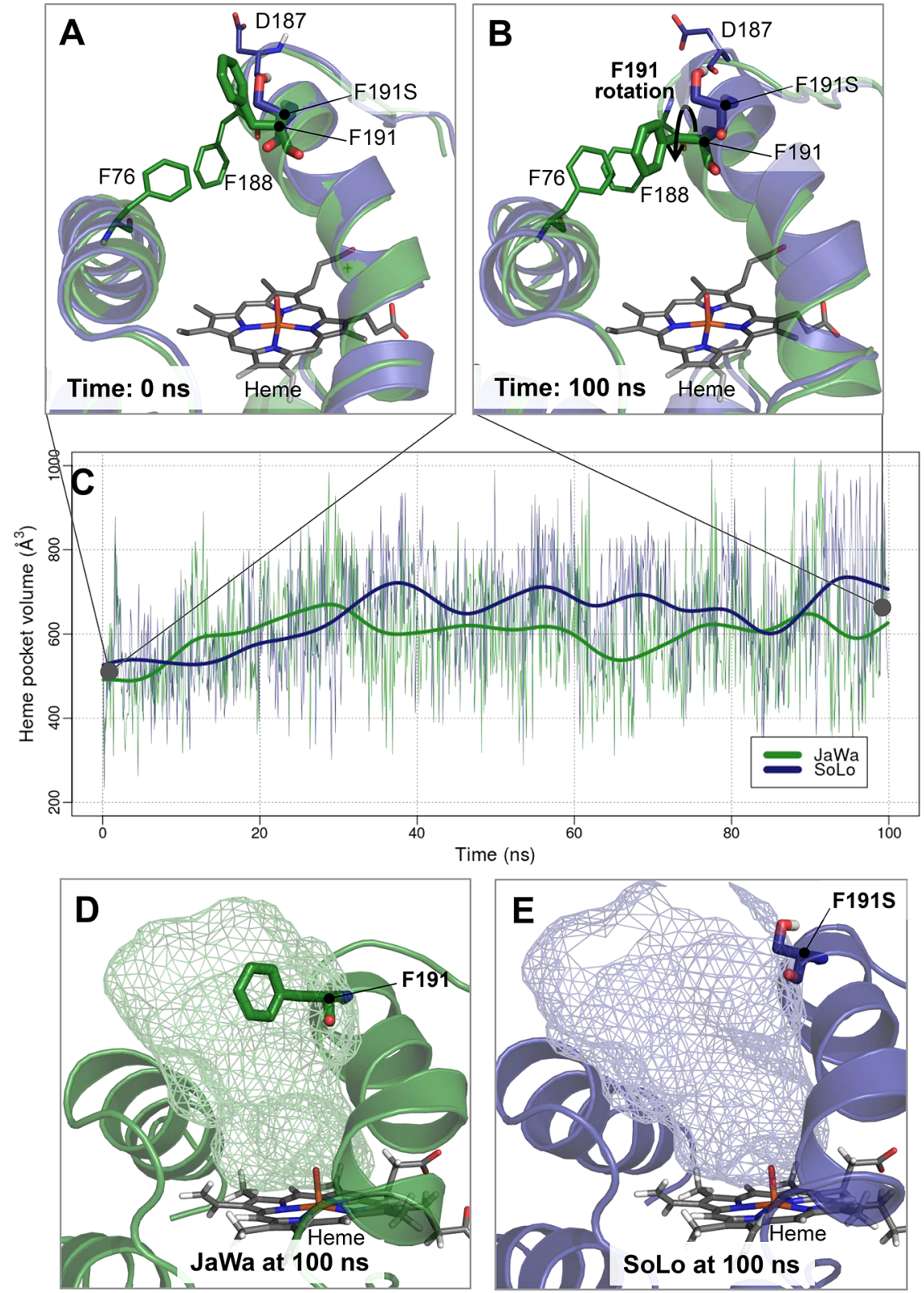

Figure 4. F191S induced structural changes along $100 \mathrm{~ns} \mathrm{MD}$. (A and B) JaWa and SoLo (colored in green and dark blue, respectively) comparison at the beginning $(0 \mathrm{~ns}$, panel A) and at the end (100 ns, panel B) of the MD simulation. Simulations show that, while the F191 residue in JaWa causes a displacement of the $\alpha$-helix hosting it and leads to the reduction of the heme cavity, in the SoLo variant F191S avoids the heme pocket hydrophobicity and tends to be buried into the $\alpha$-helix holding it, interacting mainly with nearby residues (a hydrogen bond with D187 is conserved $87 \%$ among the MD). (C) Heme cavity volume tracking along $100 \mathrm{~ns}$ MD simulations for JaWa and SoLo variants, calculated with MDpocket every $0.1 \mathrm{~ns}$. Smoothed volume of the pocket is shown in thick lines. (D and E) Heme binding pocket volume representation as a mesh surface for JaWa (panel D) and SoLo (panel E) variants after $100 \mathrm{~ns}$ MD simulation.

Figure S11 in the Supporting Information) in overall 15.2\% isolated yield. It should, however, be emphasized that neither the synthetic reaction nor the isolation and purification procedure were optimized.

\section{CONCLUSIONS AND OUTLOOK}

By using $\mathrm{H}_{2} \mathrm{O}_{2}$ as a final electron acceptor and exclusive oxygen donor, UPO carries out a variety of oxygen-transfer reactions, and as such, it is considered by many to be "taking the baton" from P450s in the field of synthetic organic chemistry. ${ }^{19,29-31}$ In this study, we designed a highly active and stable UPO variant that behaves as a self-sufficient and efficient biocatalyst for the selective synthesis of 5'-OHP, irrespective of the presence of radical scavengers in the reaction. The UPO mutant shows the highest regioselectivity and TTN for the synthesis of 5 '-OHP reported so far. When we compare it with the best engineered P450 BM3 heme domain peroxygenase, the SoLo mutant surpasses it roughly by 9000 -fold. ${ }^{10-14}$ More significantly, with the assistance of $\mathrm{a}_{2} \mathrm{O}_{2}$ in situ generation system based on an enzyme cascade reaction with methanol as the sacrificial electron donor for the reductive activation of $\mathrm{O}_{2}{ }^{28}$ this UPO variant outperforms any natural or engineered hydroxylating catalyst described to date going one step closer to the industrial needs. ${ }^{32}$ 


\section{MATERIALS AND METHODS}

Materials. ABTS, benzyl alcohol, Taq DNA polymerase, ascorbic acid, and the Yeast Transformation kit were from Sigma-Aldrich/Merck (Darmstadt, Germany). 5'-Hydroxypropranolol (5'-OHP) was purchased from Santa Cruz Biotechnology (Santa Cruz, CA, U.S.A.), and D,L-propranolol hydrochloride was purchased from ACROS Organics (Belgium). The PfuUltra was acquired from Agilent. The BamHI and XhoI were from New England Biolabs (MA, U.S.A.), and the $S$. cerevisiae strain BJ5465 was purchased from LGCPromochem (Barcelona, Spain). The Zymoclean Gel DNA Recovery kit and the Zymoprep Yeast Plasmid Miniprep kit were from Zymo Research (Orange, CA, U.S.A.). The NucleoSpin Plasmid kit was from Macherey-Nagel (Düren, Germany), and the primers were synthesized by Metabion (Bayern, Germany). All chemicals were reagent-grade purity or analytical standards.

Culture Media. S. cerevisiae culture media was prepared as reported elsewhere. ${ }^{16}$

Laboratory Evolution. All PCR products were loaded onto a preparative agarose gel and purified by use of the Zymoclean Gel DNA Recovery kit. The recovered DNA fragments were cloned under the control of the GAL1 promoter of the pJRoC30 expression shuttle vector, with use of BamHI and XhoI to linearize the plasmid and to remove the parent gene. The linearized vector was loaded onto a preparative agarose gel and purified with the Zymoclean Gel DNA Recovery kit.

Focused evolution at D187-V248 segment: The region between Asp187-Val248 selected from docking experiments was subjected to MORPHING (mutagenic organized recombination process by homologous in vivo grouping). ${ }^{24}$ Two Mutagenic PCRs were prepared in a final volume of $50 \mu \mathrm{L}$ containing 3\% DMSO, $90 \mathrm{nM}$ MJaWa Fw ( $5^{\prime}$-gcgcattcaagactc-

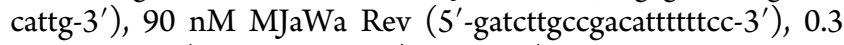
$\mathrm{mM}$ dNTPs (0.075 mM each), $\mathrm{MnCl}_{2}$ (mutational loads of 0.1 $\mathrm{mM}$ and $0.2 \mathrm{mM}), 1.5 \mathrm{mM} \mathrm{MgCl}, 0.05 \mathrm{U} / \mu \mathrm{L}$ Taq DNA polymerase, and $1 \mathrm{ng} / \mu \mathrm{L}$ template. The amplification parameters were $94{ }^{\circ} \mathrm{C}$ for $2 \mathrm{~min}$ ( 1 cycle); $94{ }^{\circ} \mathrm{C}$ for $45 \mathrm{~s}$, $48{ }^{\circ} \mathrm{C}$ for $30 \mathrm{~s}$, and $72{ }^{\circ} \mathrm{C}$ for $90 \mathrm{~s}$ ( 28 cycles); and $72{ }^{\circ} \mathrm{C}$ for 10 min ( 1 cycle). The remaining portions of the whole JaWa gene were amplified by high-fidelity PCR in a final volume of $50 \mu \mathrm{L}$ containing 3\% DMSO, $0.5 \mu \mathrm{M}$ HFJaWa Fw (5'-caggctcatcctatgcagccc- $\left.3^{\prime}\right)$ and $0.5 \mu \mathrm{M}$ RMLC ( $5^{\prime}$-gggagggcgtgaatgtaagc- $\left.3^{\prime}\right)$ or $0.5 \mu \mathrm{M}$ HFJaWa Rev ( $5^{\prime}$-caaaggagaaattggggttggtcg- $\left.3^{\prime}\right)$ and $0.5 \mu \mathrm{M}$ RMLN $\left(5^{\prime}\right.$-cctctatactttaacgtcaagg- $\left.3^{\prime}\right)$ for the other high fidelity fragment, $1 \mathrm{mM}$ dNTPs $(0.25 \mathrm{mM}$ each), $0.05 \mathrm{U} / \mu \mathrm{L}$ PfuUltra DNA polymerase, and $2 \mathrm{ng} / \mu \mathrm{L}$ template. High-fidelity PCR was carried out on a gradient thermocycler using the following parameters: $95{ }^{\circ} \mathrm{C}$ for $2 \mathrm{~min}(1 \mathrm{cycle}) ; 95^{\circ} \mathrm{C}$ for $45 \mathrm{~s}$, $48^{\circ} \mathrm{C}$ for $30 \mathrm{~s}$, and $72{ }^{\circ} \mathrm{C}$ for $90 \mathrm{~s}(28$ cycles $)$; and $72{ }^{\circ} \mathrm{C}$ for 10 min ( 1 cycle). The whole gene was in vivo reassembled and recombined by transforming the different PCR products into $S$. cerevisiae competent cells, a process facilitated by $\sim 40$ bp overhangs flanking each recombination area. ${ }^{33}$ The DNA transformation mixture was composed of linearized plasmid (100 ng) mixed with the mutagenized fragment (200 ng) and both nonmutagenized fragments $(200 \mathrm{ng})$. A total of 1220 individual clones were screened (610 clones per mutant library).

Combinatorial saturation mutagenesis (F76 and S191): three PCR reactions were carried out in a final volume of $50 \mu \mathrm{L}$ containing 3\% DMSO, $0.3 \mathrm{mM}$ dNTPs (0.075 mM each), 0.05
$\mathrm{U} / \mu \mathrm{L}$ PfuUltra DNA polimerase, and $2 \mathrm{ng} / \mu \mathrm{L}$ template but each of them with different primers. PCR 1 with $0.25 \mu \mathrm{M}$ of RMLN, $0.25 \mu \mathrm{M}$ of F76 VHG R ( 5 '-gcaagtccgtaatgagattgccgtccacaaggtgggccgcatatgtggccdbgattgcggc-3'), $0.25 \mu \mathrm{M}$ of $\mathrm{F} 76$ NDT R (5'-gcaagtccgtaatgagattgccgtccacaaggtgggccgcatatgtggcahngattgcggc- $\left.3^{\prime}\right)$ and $0.25 \mu \mathrm{M}$ of F76 TGG R (5'gcaagtccgtaatgagattgccgtccacaaggtgggccgcatatgtggcccagattgcggc$\left.3^{\prime}\right)$. PCR 2 with $0.25 \mu \mathrm{M}$ of HF F (5'-gcggcccaccttgtggacggcaatctcattacggacttgc- $\left.3^{\prime}\right), \quad 0.25 \mu \mathrm{M}$ of S191 VHG R (5'cccatccacaaaaagattcgcggggaaggtggtctcgccgtaagcagtcdbgaacctaaag-3'), $0.25 \mu \mathrm{M}$ of S191 NDT R (5'-cccatccacaaaaagattcgcggggaaggtggtctcgccgtaagcagtahngaacctaaag- $\left.3^{\prime}\right)$, and 0.25 $\mu \mathrm{M}$ of S191 TGG R (5'-cccatccacaaaaagattcgcggggaaggtggtctcgccgtaagcagtccagaacctaaag- $\left.3^{\prime}\right)$. PCR 3 with 0.25 $\mu \mathrm{M}$ of HF F-RMLC ( $5^{\prime}$-cggcgagaccaccttccccgcgaatctttttgtggatggg- $\left.3^{\prime}\right)$ and $0.25 \mu \mathrm{M}$ of RMLC. Codon substitutions are shown in italics (where $\mathrm{N}=\mathrm{A} / \mathrm{T} / \mathrm{C} / \mathrm{G} ; \mathrm{D}=$ no $\mathrm{C} ; \mathrm{V}=$ no $\mathrm{T}, \mathrm{H}$ $=$ no $\mathrm{G}$; y $\mathrm{B}=$ no $\mathrm{A}) .{ }^{34} \mathrm{PCR}$ reactions were carried out on a gradient thermocycler using the following parameters: $95{ }^{\circ} \mathrm{C}$ for 2 min $(1$ cycle $) ; 95{ }^{\circ} \mathrm{C}$ for $45 \mathrm{~s}, 48{ }^{\circ} \mathrm{C}$ for $45 \mathrm{~s}$, and $72{ }^{\circ} \mathrm{C}$ for $60 \mathrm{~s}$ ( 28 cycles); and $72{ }^{\circ} \mathrm{C}$ for $10 \mathrm{~min}$ ( 1 cycle). The combinatorial saturation mutagenesis library was transformed into $S$. cerevisiae and the whole genes were in vivo reassembled and recombined by transforming the different PCR products into $S$. cerevisiae competent cells, a process facilitated by $\sim 40 \mathrm{bp}$ overhangs (underlined in each primer) flanking each recombination area. ${ }^{33}$ The DNA transformation mixtures were composed of a linearized plasmid (100 ng) mixed with the rest of the appropriate fragments $(200 \mathrm{ng})$. A total of 1480 clones were screened according to 22-trick method guidelines. $^{34}$

Saturation mutagenesis at F69, F121, F199: saturation mutagenesis was carried out using degenerated NNK codons $(\mathrm{N}=\mathrm{A} / \mathrm{T} / \mathrm{C} / \mathrm{G} ; \mathrm{K}=\mathrm{T} / \mathrm{G}, \mathrm{M}=\mathrm{A} / \mathrm{C})$, creating three different libraries. Library F69: two PCR reactions were carried out in a final volume of $50 \mu \mathrm{L}$ containing $3 \%$ DMSO, $0.2 \mathrm{mM}$ dNTPs (0.05 mM each), $0.02 \mathrm{U} / \mu \mathrm{L}$ iProof DNA polymerase, $2 \mathrm{ng} / \mu \mathrm{L}$ template (SoLo) with $0.5 \mu \mathrm{M}$ RMLN and $0.5 \mu \mathrm{M}$ F69 R (5'gaagattgcggcttgattgtcmnnattgaatc- $\left.3^{\prime}\right)$, or $0.5 \mu \mathrm{M}$ RMLC and $0.5 \mu \mathrm{M}$ F69 F (5'-cgcggttcaggaaggattcaatnnkgacaatc- $\left.3^{\prime}\right)$. Library F121: two PCR reactions were carried out in a final volume of $50 \mu \mathrm{L}$ containing 3\% DMSO, $0.2 \mathrm{mM}$ dNTPs $(0.05$ $\mathrm{mM}$ each), $0.02 \mathrm{U} / \mu \mathrm{L}$ iProof DNA polymerase, $2 \mathrm{ng} / \mu \mathrm{L}$ template (SoLo) with $0.5 \mu \mathrm{M}$ RMLN and $0.5 \mu \mathrm{M}$ F121 R (5'catactggcgtcgecttcmnnggtgccatgc- $3^{\prime}$ ), or $0.5 \mu \mathrm{M}$ RMLC and 0.5 $\mu \mathrm{M}$ F121 F ( $5^{\prime}$-ggactcaatgagcatggcaccnnkgaaggcg- $\left.3^{\prime}\right)$. Library F199: two PCR reactions were carried out in a final volume of $50 \mu \mathrm{L}$ containing $3 \%$ DMSO, $0.2 \mathrm{mM}$ dNTPs (0.05 mM each), $0.02 \mathrm{U} / \mu \mathrm{L}$ iProof DNA polymerase, $2 \mathrm{ng} / \mu \mathrm{L}$ template (SoLo) with $0.5 \mu \mathrm{M}$ RMLN and $0.5 \mu \mathrm{M}$ F199 R (5'-ccacaaaaagattcgcgggmnnggtggtctcg- $\left.3^{\prime}\right)$, or $0.5 \mu \mathrm{M}$ RMLC and $0.5 \mu \mathrm{M}$ F199 F ( $5^{\prime}$-ctactgcttacggcgagaccaccnnkcccgcg-3'). PCR reactions were carried out on a gradient thermocycler using the following parameters: $98{ }^{\circ} \mathrm{C}$ for $30 \mathrm{~s}(1$ cycle $) ; 98{ }^{\circ} \mathrm{C}$ for $10 \mathrm{~s}$, $48{ }^{\circ} \mathrm{C}$ for $30 \mathrm{~s}$, and $72{ }^{\circ} \mathrm{C}$ for $30 \mathrm{~s}$ ( 28 cycles $)$; and $72{ }^{\circ} \mathrm{C}$ for 10 min ( 1 cycle). Each library was transformed independently, and the whole genes were in vivo reassembled and recombined by transforming the different PCR products into S. cerevisiae competent cells, a process facilitated by $\sim 40$ bp overhangs flanking each recombination area. ${ }^{33}$ The DNA transformation mixtures were composed of linearized plasmid (100 ng) mixed with the rest of the appropriate fragments (200 ng). Each library contained 170 clones. 
High Throughput Dual screening: Individual clones were picked and inoculated in sterile 96-well plates (Greiner BioOne, GmbH, Germany), referred to as master plates, containing $200 \mu \mathrm{L}$ of SEM per well. In each plate, column number 6 was inoculated with the parent type, and one well (H1-control) was inoculated with $S$. cerevisiae transformed with pJRoC30-MtL plasmid (laccase without activity). Plates were sealed with parafilm to prevent evaporation and incubated at 30 ${ }^{\circ} \mathrm{C}, 220 \mathrm{rpm}$ and $80 \%$ relative humidity in a humidity shaker (Minitron, Infors, Switzerland) for 5 days. The master plates were centrifuged (Eppendorf 5810R centrifuge, Germany) for $10 \mathrm{~min}$ at $2500 \mathrm{~g}$ and $4{ }^{\circ} \mathrm{C}$. Aliquots of the supernatants $(20 \mu \mathrm{L})$ were transferred from the master plates to two replica plates with the aid of a liquid handler robotic station Freedom EVO (Tecan, Switzerland). A total of $50 \mu \mathrm{L}$ of the reaction mixture (with or without ascorbic acid) was added to the two replica plates with the help of a pipetting robot (Multidrop Combi Reagent Dispenser, Thermo Scientific, MA, U.S.A.). The reaction mixture for replica plate 1 contained $50 \mathrm{mM}$ potassium phosphate buffer ( $\mathrm{pH} 7.0$ ), $5 \mathrm{mM}$ propranolol, and $2 \mathrm{mM}$ $\mathrm{H}_{2} \mathrm{O}_{2}$. The reaction mixture for replica plate 2 contained 50 $\mathrm{mM}$ potassium phosphate buffer ( $\mathrm{pH} 7.0), 5 \mathrm{mM}$ propranolol, $2 \mathrm{mM} \mathrm{H}_{2} \mathrm{O}_{2}$, and $4 \mathrm{mM}$ ascorbic acid. Replica plates 1 and 2 were incubated at room temperature for 30 and $60 \mathrm{~min}$, respectively. Afterward, the amount of 5'-OHP formed in each well was determined by the 4-aminoantipyrine (4-AAP) assay ${ }^{22}$ (Figures S1-S3 in the Supporting Information). Plates were stirred briefly, and absorption at $530 \mathrm{~nm}$ was recorded in a plate reader (SPECTRAMax Plus 384, Molecular Devices, U.S.A.). The values were normalized against the parent type of the corresponding plate, and selected variants came from the ratio between the values obtained in the absence (peroxygenative +peroxidative activities) and in the presence (peroxygenative activity) of ascorbic acid. To rule out the selection of false positives, two rescreenings were carried out as described elsewhere. $^{20}$

Production, Purification, and Biochemical Characterization. AaeUPO wildtype and recombinant UPO (PaDa-I, JaWa, and SoLo variants) were produced and purified as described before with minor modifications. ${ }^{11,16,20}$ Recombinant UPO purification was achieved by cationic exchange chromatography and anion exchange chromatography (ÄKTA purifier, GE Healthcare, WI, U.S.A.). The crude extract was concentrated and dialyzed in sodium phosphate/citrate $20 \mathrm{mM}$ at $\mathrm{pH} 3.3$ (buffer A) by tangential ultrafiltration (Pellicon; Millipore, Temecula, CA, U.S.A.) through a $10-\mathrm{kDa}$-pore-size membrane (Millipore) by means of a peristaltic pump (Masterflex Easy Load; Cole-Parmer, Vernon Hills, IL, U.S.A.). The sample was filtered and loaded onto a strong cation-exchange column (HiTrap SP FF GE Healthcare) preequilibrated with buffer $A$. The proteins were eluted with a linear gradient from 0 to $40 \%$ of buffer A within $60 \mathrm{~mL}$ of $\mathrm{NaCl}$ and from 40 to $100 \%$ within $5 \mathrm{~mL}$ at a flow rate of $1 \mathrm{~mL} / \mathrm{min}$. Fractions with UPO activity vs ABTS were harvested, concentrated, dialyzed against buffer Tris $\mathrm{HCl} 20 \mathrm{mM}$ at $\mathrm{pH}$ 7.8 (buffer B), and loaded onto a $10 \mu \mathrm{m}$ high resolution anionexchange Biosuite $Q$ column (Waters) pre-equilibrated with buffer $\mathrm{B}$. The proteins were eluted with a linear gradient from 0 to $20 \%$ within $40 \mathrm{~mL}$ of $\mathrm{NaCl}$ and from 20 to $100 \%$ within 5 $\mathrm{mL}$ at a flow rate of $1 \mathrm{~mL} / \mathrm{min}$. The fractions with UPO activity vs. ABTS were pooled, dialyzed against buffer potassium phosphate $10 \mathrm{mM}$ at $\mathrm{pH} 7.0$ and stored at $4{ }^{\circ} \mathrm{C}$.
Steady-state kinetic constants: ABTS kinetics were measured in sodium phosphate/citrate buffer ( $\mathrm{pH} 4.0,100 \mathrm{mM})$, containing $\mathrm{H}_{2} \mathrm{O}_{2}(2 \mathrm{mM})$ and for propranolol in potassium phosphate buffer $(\mathrm{pH} 7.0,50 \mathrm{mM})$ containing $\mathrm{H}_{2} \mathrm{O}_{2}(2 \mathrm{mM})$. For $\mathrm{H}_{2} \mathrm{O}_{2}$, benzyl alcohol was used as a reducing substrate under the corresponding saturated conditions. Reactions were performed in triplicate, and substrate oxidations were followed through spectrophotometric changes $\left(\varepsilon_{418} \mathrm{ABTS}^{\bullet+}=36000\right.$ $\mathrm{M}^{-1} \mathrm{~cm}^{-1} ; \varepsilon_{325} 5^{\prime}$-OHP $=1996 \mathrm{M}^{-1} \mathrm{~cm}^{-1}$, and $\varepsilon_{280}$ benzaldehyde $=1400 \mathrm{M}^{-1} \mathrm{~cm}^{-1}$ ).

HPLC analysis: The reaction mixtures were analyzed by reversed-phase chromatography (HPLC) with equipment consisting of a tertiary pump (Varian/Agilent Technologies) coupled to an autosampler (Merck Millipore) and an Zorbax Eclipse plus $\mathrm{C} 18(15 \mathrm{~cm} \times 4,6 \mathrm{~cm})$ column at $40{ }^{\circ} \mathrm{C}$. Detection was performed with a PDA (Varian/Agilent Technologies). The mobile phase was a gradient from $10 \%$ methanol and $90 \%$ $d d \mathrm{H}_{2} \mathrm{O}$ (both with $0.1 \%$ acetic acid) to $90 \%$ methanol and $10 \%$ $d d \mathrm{H}_{2} \mathrm{O}$ at a flow rate of $0.8 \mathrm{~mL} / \mathrm{min}$. The reaction was quantified at $280 \mathrm{~nm}$ (from HPLC standards). Reaction mixtures contained $0.03 \mu \mathrm{M}$ purified enzyme, $5 \mathrm{mM}$ propranolol, and $2 \mathrm{mM} \mathrm{H}_{2} \mathrm{O}_{2}$ in $50 \mathrm{mM}$ potassium phosphate $\mathrm{pH} 7.0$ (0.5 mL final volume). After $60 \mathrm{~min}$ at room temperature, the reaction was stopped by heating $10 \mathrm{~min}$ at $70{ }^{\circ} \mathrm{C}$ and cooling $5 \mathrm{~min}$ at $4{ }^{\circ} \mathrm{C}$ (see Figure $2 \mathrm{C}$ ). Total turnover numbers were calculated from the reaction that contained $0.03 \mu \mathrm{M}$ purified enzyme, $5 \mathrm{mM}$ propranolol, and pulses of $2 \mathrm{mM} \mathrm{H} \mathrm{H}_{2} \mathrm{O}_{2}$ every $10 \mathrm{~min}$ in $50 \mathrm{mM}$ potassium phosphate buffer $\mathrm{pH} 7.0$ ( $0.5 \mathrm{~mL}$ final volume). Reactions were stopped at different times $(10-120 \mathrm{~min})$ as described before (see Figure $2 \mathrm{~A}, \mathrm{~B})$. In the determination of $5^{\prime}$-hydroxypropranolol $\left(5^{\prime}-\mathrm{OHP}\right)$ consumption by UPO, the mixture contained $0.03 \mu \mathrm{M}$ purified enzyme, $0.5 \mathrm{mM} 5^{\prime}-\mathrm{OHP}, 20 \%$ methanol $20 \%$ and $2 \mathrm{mM} \mathrm{H} \mathrm{H}_{2} \mathrm{O}_{2}$ in $50 \mathrm{mM}$ potassium phosphate buffer $\mathrm{pH} 7.0$ ( $0.5 \mathrm{~mL}$ final volume). The reaction was started by the addition of the $\mathrm{H}_{2} \mathrm{O}_{2}$ and stopped at different times $(2-10 \mathrm{~min})$ as described before (see Figure 2D). Samples of each experiment $(20 \mu \mathrm{L})$ were injected and analyzed. Standard deviations were lower than 5\% in all experiments. Products were identified and quantified against authentic standards by the HPLC method mentioned above.

Kinetic thermostability: The thermostability of the different UPO samples was estimated by assessing their $T_{50}$ values using 96/384 well gradient thermocyclers. Appropriate UPO dilutions were prepared with the help of the robot in such a way that $20 \mu \mathrm{L}$ aliquots gave rise to a linear response in the kinetic mode. Then, $50 \mu \mathrm{L}$ were used for each point in the gradient scale, and a temperature gradient profile ranging from 30 to $80{ }^{\circ} \mathrm{C}$ was established as follows (in ${ }^{\circ} \mathrm{C}$ ): $30.0,31.7,34.8$, $39.3,45.3,49.9,53.0,55.0,56.8,59.9,64.3,70.3,75.0,78.1$, and 80.0. After a $10 \mathrm{~min}$ incubation, samples were chilled on ice for $10 \mathrm{~min}$ and further incubated at room temperature for $5 \mathrm{~min}$. Afterward, $20 \mu \mathrm{L}$ of samples were subjected to the ABTS colorimetric assay described elsewhere. ${ }^{20}$ The thermostability values were deduced from the ratio between the residual activities incubated at different temperature points and the initial activity at room temperature.

Reaction Optimization and Product Identification. Production of 5'-OHP by SoLo coupled to an in situ $\mathrm{H}_{2} \mathrm{O}_{2}$ generation system: For in situ $\mathrm{H}_{2} \mathrm{O}_{2}$ generation, $10 \mathrm{nM}$ SoLo mutant, $10 \mathrm{nM}$ alcohol oxidase from Pichia pastoris (AOx), and $600 \mathrm{nM}$ formate dismutase from Pseudomonas putida (FDM) in combination with $200 \mathrm{mM}$ methanol were used. ${ }^{28}$ Reactions 
were performed at $30^{\circ} \mathrm{C}$ and $600 \mathrm{rpm}$ in $100 \mathrm{mM}$ potassium phosphate buffer $\mathrm{pH} 7.0$ with $10 \mathrm{mM}$ of propranolol in a total volume of $375 \mu \mathrm{L}$ using a thermo shaker device (Eppendorf, Germany). After $3 \mathrm{~h}$, the reactions were stopped by heat inactivation for $10 \mathrm{~min}$ at $70{ }^{\circ} \mathrm{C}$, followed by cooling the sample and separation of precipitate by centrifugation at $5{ }^{\circ} \mathrm{C}$. Quantification of 5'-OHP was carried out by HPLC analytics. HPLC measurements were performed at $40{ }^{\circ} \mathrm{C}$ on a Shimadzu LC-20 system with a Shimadzu SPD-M20A Photo Diode Array detector using Waters Xterra RP18 column $(4.6 \times 150 \mathrm{~mm}, 3.5$ $\mu \mathrm{m})$. For the mobile phase, acetonitrile (ACN) and water containing 5\% ACN and $0.1 \%$ trifluoroacetic acid (TFA) were used. The separation was performed in an isocratic mode at a flow rate of $1.0 \mathrm{~mL} / \mathrm{min}$ while increasing the $\mathrm{ACN}$ concentration in three steps to finally $100 \%$ : $25 \%, 4 \mathrm{~min}$ hold; 50\%, 4 min hold; and 100\%, 3 min hold. The reaction was quantified at $280 \mathrm{~nm}$ based on a calibration using 5'-OHP standard.

Semipreparative production of 5'-OHP: For the semipreparative production of $5^{\prime}-\mathrm{OHP}, 50 \mathrm{mM}$ propranolol was dissolved in $100 \mathrm{mM}$ potassium phosphate buffer $\mathrm{pH} 7.0$ (10 $\mathrm{mL}$ total volume). Reactions were performed at $30{ }^{\circ} \mathrm{C}$ while gently mixing (neoLab rotator, mode C2, $20 \mathrm{rpm}$, Germany) in presence or absence of $40 \mathrm{mM}$ of AA using $0.5 \mu \mathrm{M}$ of SoLo. The reaction was started by the addition of $5 \mathrm{mM}$ tert-butyl hydroperoxide (tert-BuOOH). Every hour, $5 \mathrm{mM}$ tert-BuOOH was added and $200 \mu \mathrm{L}$ of each reaction time were taken for $5^{\prime}$ OHP quantification by HPLC. After $9 \mathrm{~h}, 5 \mathrm{~mL}$ of the reaction mixture was used for 5'-OHP isolation. The solution was acidified $(200 \mu \mathrm{L}, 37 \% \mathrm{HCl})$, extracted with ethyl acetate $(3 \times 5$ $\mathrm{mL}$ ), and dried with $\mathrm{MgSO}_{4}$, and the solvent was removed under reduced pressure. The crude product was purified by column chromatography using silica gel (60 Å, 230-400 mesh) with a dichloromethane (DCM)/methanol eluent (8:2). Separation follow, using thin layer chromatography (TLC) on silica gel-coated plates (Macherey-Nagel, Polygram SIL G/ UV254) with a DCM/methanol solvent mixture (9:1).

NMR analytics: NMR spectra were recorded on an Agilent $400(400 \mathrm{MHz})$ spectrometer in methanol- $d_{4}$. Chemical shifts are given in ppm with respect to tetramethylsilane. Coupling constants are reported as $J$ values in $\mathrm{Hz}$ (Figure $\mathrm{S} 11$ in the Supporting Information).

Computational Analysis. System preparation for molecular modeling: The starting structure for PELE (Protein Energy Landscape Exploration) simulations with AaeUPO was the Agrocybe aegerita peroxygenase crystal structure (PDB ID: 2YOR). For the different UPO mutants, the crystal structure of PaDa-I (at a resolution of $1.5 \AA$, courtesy of Prof. Julia Sanz, IQFR-CSIC, Madrid, unpublished material) was used for modeling. Since the optimal $\mathrm{pH}$ for propranolol peroxygenation and subsequent $5^{\prime}$-OHP peroxidation is 7.0 , all of the structures were prepared accordingly with the aid of the Schrödinger Protein Preparation Wizard ${ }^{35}$ and the $\mathrm{H}++$ web server. ${ }^{36}$ All acidic residues were deprotonated. Histidines were $\delta$-protonated, with the exception of His 82 ( $\varepsilon$-protonated) and His 118 and His 251 (double-protonated). To relax the systems after mutations insertion and to investigate their possible effect on the protein structure, $5 \mathrm{~ns}$ of Molecular Dynamics simulation (MD) were performed with Desmond ${ }^{37}$ on the JaWa and SoLo structures. Finally, the heme site was modeled as compound I after being fully optimized in the protein environment with quantum mechanics/molecular mechanics (QM/MM) using QSite. ${ }^{38}$ Propranolol and 5'-OHP molecules were also optimized with Jaguar ${ }^{39}$ at the DFT/M06 level with the $6-31 \mathrm{G}^{* *}$ basis and PBF implicit solvent in order to obtain their electrostatic potential atomic charges.

Protein energy landscape exploration (PELE) computational analysis: Once all protein and ligand structures were prepared, heme binding site explorations were performed with PELE. ${ }^{26}$ Substrates were manually placed in identical positions at the entrance of the heme-access channel, and PELE simulations were carried out in two different stages. First, ligands were driven from the solvent to the UPO heme binding site. Then, once the center of mass of the ligand was within $6 \AA$ of the heme catalytic oxygen, it was free to explore the active site. The results presented here are based on 160 independent $48 \mathrm{~h}$ PELE simulations. Moreover, in an attempt to increase the sampling for 5'-OHP diffusion, additional PELE simulations were performed for this substrate. Representative structures at distances lower than $10 \AA$ (considering the distance between the reactive $\mathrm{O}$-heme atom and the $\mathrm{H}_{5}$ substrate atom) were selected using binning widths of $1 \AA$ from previous PELE simulations and used as starting structures for the new ones. New simulations were set up to freely explore the active site, and a total of 196 independent $48 \mathrm{~h}$ simulations were run.

Molecular Dynamics and MDpocket: To study the changes caused by F191S mutation, 100 ns MD simulations were performed with JaWa and SoLo using Desmond. ${ }^{37}$ To prepare the system for MD, previously mentioned prepared JaWa and SoLo systems were placed inside an orthorhombic box containing SPC explicit waters and ions to neutralize the system at a concentration of $0.15 \mathrm{M} \mathrm{NaCl}$. From the solvated system, $\mathrm{MD}$ simulations were run with the following parameters: the OPLS-2005 force field, the temperature was regulated with a Nose-Hoover chain thermostat with a relaxation time of $1.0 \mathrm{ps}$, the pressure with the MartynaTobias-Klein barostat with isotropic coupling and a relaxation time of $2.0 \mathrm{ps}$, and finally, the production phase was run over the course of $100 \mathrm{~ns}$ using the NPT canonical ensemble at 300 K. From MD simulations, structures at every $0.1 \mathrm{~ns}$ were extracted and used for volume pocket calculation with MDpocket, $^{27}$ a fast and open-source tool for protein pocket (cavity) detection on molecular dynamic trajectories or other conformational ensembles.

\section{ASSOCIATED CONTENT}

\section{S Supporting Information}

This material is available free of charge on the ACS Publications Web site. The Supporting Information is available free of charge on the ACS Publications website at DOI: 10.1021/ acscatal.8b01004.

Additional material pertaining to experimental results (Figures S1-S11) (PDF)

Movie showing diffusion and binding site positioning of propranolol in AaeUPO and SoLo mutant (AVI)

\section{AUTHOR INFORMATION}

\section{Corresponding Author}

*E-mail: malcalde@icp.csic.es.

\section{Notes}

The authors declare no competing financial interest.

\section{ACKNOWLEDGMENTS}

We thank Francisco J. Plou and Paloma Santos Moriano for assistance with the HPLC-PDA analysis (ICP, CSIC, Spain). 
This work was supported by the European Union Project H2020-BBI-PPP-2015-2-720297-ENZOX2 and the COST Action CM1303 Systems Biocatalysis, the Spanish Government Projects BIO2016-79106-R-Lignolution and CTQ2016-70138$\mathrm{R}$, and the CSIC Project PIE-201580E042.

\section{REFERENCES}

(1) National Research Council Industrialization of Biology: A Roadmap to Accelerate the Advanced Manufacturing of Chemicals; The National Academies Press: Washington, DC, 2015.

(2) Baillie, T. A.; Cayen, M. N.; Fouda, H.; Gerson, R. J.; Green, J. D.; Grossman, S. J.; Klunk, L. J.; LeBlanc, B.; Perkins, D. G.; Shipley, L. A. Drug metabolites in safety testing. Toxicol. Appl. Pharmacol. 2002, 182, 188-196.

(3) Atrakchi, A. H. Interpretation and considerations on the safety evaluation of human drug metabolites. Chem. Res. Toxicol. 2009, 22, $1217-1220$.

(4) Guengerich, F. P. Safety Assessment of Stable Drug Metabolites. Chem. Res. Toxicol. 2009, 22, 237-238.

(5) Al-Majed, A. A.; Bakheit, A. H. H.; Abdel Aziz, H. A.; Alajmi, F. M.; AlRabiah, H. Propranolol. In Profiles of Drug Substances, Excipients and Related Methodology; Brittain, H. G., Ed.; Elsevier: United Kingdom, 2017; Vol. 42, pp 287-338.

(6) Greenslade, F. C.; Newquist, K. L. In vitro measurement of the beta-adrenergic blocking properties of ORF 12592, the 5-hydroxy analog of propranolol. Arch. Int. Pharmacodyn. Ther 1978, 233, 270280.

(7) Oatis, J. E., Jr; Russell, M. P.; Knapp, D. R.; Walle, T. RingHydroxylated Propranolol: Synthesis and P-Receptor Antagonist and Vasodilating Activities of the Seven Isomers. J. Med. Chem. 1981, 24, 309-314.

(8) Kumamoto, T.; Aoyama, N.; Nakano, S.; Ishikawa, T.; Narimatsu, S. Synthesis of enantiomeric 4-hydroxypropranolols from 1,4dihydroxynaphthalene. Tetrahedron: Asymmetry 2001, 12, 791-795.

(9) Eiben, S.; Kaysser, L.; Maurer, S.; Kühnel, K.; Urlacher, V. B.; Schmid, R. D. Preparative use of isolated CYP102 monooxygenases a critical appraisal. J. Biotechnol. 2006, 124, 662-669.

(10) Otey, C. R.; Bandara, G.; Lalonde, J.; Takahashi, K.; Arnold, F. $\mathrm{H}$. Preparation of human metabolites of propranolol using laboratoryevolved bacterial cytochromes P450. Biotechnol. Bioeng. 2006, 93, 494-499.

(11) Ullrich, R.; Nüske, J.; Scheibner, K.; Spantzel, J.; Hofrichter, M. Novel haloperoxidase from the agaric basidiomycete Agrocybe aegerita oxidizes aryl alcohols and aldehydes. Appl. Environ. Microbiol. 2004, 70, $4575-4581$.

(12) Hofrichter, M.; Ullrich, R. Oxidations catalyzed by fungal peroxygenases. Curr. Opin. Chem. Biol. 2014, 19, 116-125.

(13) Poraj-Kobielska, M.; Kinne, M.; Ullrich, R.; Scheibner, K.; Kayser, G.; Hammel, K. E.; Hofrichter, M. Preparation of human drug metabolites using fungal peroxygenases. Biochem. Pharmacol. 2011, 82, 789-796.

(14) Kinne, M.; Poraj-Kobielska, M.; Aranda, E.; Ullrich, R.; Hammel, K. E.; Scheibner, K.; Hofrichter, M. Regioselective preparation of 5-hydroxypropranolol and 4'-hydroxydiclofenac with a fungal peroxygenase. Bioorg. Med. Chem. Lett. 2009, 19, 3085-3087.

(15) Kiebist, J.; Holla, W.; Heidrich, J.; Poraj-Kobielska, M.; Sandvoss, M.; Simonis, R.; Gröbe, G.; Atzrodt, J.; Hofrichter, M.; Scheibner, K. One-pot synthesis of human metabolites of SAR548304 by fungal peroxygenases. Bioorg. Med. Chem. 2015, 23, 4324-4332.

(16) Molina-Espeja, P.; Cañellas, M.; Plou, F. J.; Hofrichter, M.; Lucas, F.; Guallar, V.; Alcalde, M. Synthesis of 1-Naphthol by a Natural Peroxygenase Engineered by Directed Evolution. ChemBioChem 2016, 17, 341-349.

(17) Mate, D. M.; Palomino, M. A.; Molina-Espeja, P.; Martin-Diaz, J.; Alcalde, M. Modification of the peroxygenative:peroxidative activity ratio in the unspecific peroxygenase from Agrocybe aegerita by structure-guided evolution. Protein Eng., Des. Sel. 2017, 30, 189-196.
(18) Ullrich, R; Hofrichter, M. Enzymatic hydroxylation of aromatic compounds. Cell. Mol. Life Sci. 2007, 64, 271-293.

(19) Wang, Y.; Lan, D.; Durrani, R.; Hollmann, F. Peroxygenases en route to becoming dream catalysts. What are the opportunities and challenges? Curr. Opin. Chem. Biol. 2017, 37, 1-9.

(20) Molina-Espeja, P.; Garcia-Ruiz, E.; Gonzalez-Perez, D.; Ullrich, R; Hofrichter, M.; Alcalde, M. Directed evolution of unspecific peroxygenase from Agrocybe aegerita. Appl. Environ. Microbiol. 2014, 80, 3496-3507.

(21) Molina-Espeja, P.; Ma, S.; Mate, D. M.; Ludwig, R.; Alcalde, M. Tandem-yeast expression system for engineering and producing unspecific peroxygenase. Enzyme Microb. Technol. 2015, 73-74, 2933.

(22) Otey, C. R.; Joern, J. M. High-throughput screen for aromatic hydroxylation. Methods Mol. Biol. 2003, 230, 141-148.

(23) Molecular Operating Environment (MOE), version 2010; Chemical Computing Group ULC: Canada, 2010.

(24) Gonzalez-Perez, D.; Molina-Espeja, P.; Garcia-Ruiz, E.; Alcalde, M. Mutagenic Organized Recombination Process by Homologous IN vivo Grouping (MORPHING) for directed enzyme evolution. PLoS One 2014, 9, e90919.

(25) Piontek, K.; Strittmatter, E.; Ullrich, R.; Gröbe, G.; Pecyna, M. J.; Kluge, M.; Scheibner, K.; Hofrichter, M.; Plattner, D. A. Structural Basis of Substrate Conversion in a New Aromatic Peroxygenase. Cytochrome P450 functionality with benefits. J. Biol. Chem. 2013, 288, 34767-34776.

(26) Madadkar-Sobhani, A.; Guallar, V. PELE web server: atomistic study of biomolecular systems at your fingertips. Nucleic Acids Res. 2013, 41, W322-W328.

(27) Schmidtke, P.; Bidon-Chanal, A.; Luque, F. J.; Barril, X. MDpocket: open-source cavity detection and characterization on molecular dynamics trajectories. Bioinformatics 2011, 27, 3276-3285.

(28) Ni, Y.; Fernandez-Fueyo, E.; Gomez-Baraibar, A.; Ullrich, R.; Hofrichter, M.; Yanase, H.; Alcalde, M.; van Berkel, W. J. H.; Hollman, F. Peroxygenase-Catalyzed Oxyfunctionalization Reactions Promoted by the Complete Oxidation of Methanol. Angew. Chem., Int. Ed. 2016, $55,798-801$.

(29) Bormann, S.; Gomez-Baraibar, A.; Ni, Y.; Holtmann, D.; Hollmann, F. Specific oxyfunctionalisations catalysed by peroxygenases: opportunities, challenges and solutions. Catal. Sci. Technol. 2015, 5, 2038-2052.

(30) Hofrichter, M.; Kellner, H.; Pecyna, M. J.; Ullrich, R. Fungal Unspecific Peroxygenases: Heme-Thiolate Proteins That Combine Peroxidase and Cytochrome P450 Properties. In Monooxygenase, Peroxidase and Peroxygenase Properties and Mechanisms of Cytochrome P450; Hrycay, E. G., Bandiera, S. M., Eds.; Advances in Experimental Medicine and Biology; Springer International Publishing: Basel, Switzerland, 2015; Vol. 851, pp 341-368.

(31) Molina-Espeja, P.; Gomez de Santos, P.; Alcalde, M. In Directed evolution of unspecific peroxygenase In: Directed Enzyme Evolution: Advances and Applications; Alcalde, M., Ed.; Springer International Publishing: Basel, Switzerland, 2017; pp 127-143.

(32) Gomez de Santos, P.; Molina-Espeja, P.; Plou, F. J.; Alcalde, M. Regioselective synthesis of 5 -hydroxypropranolol by aromatic peroxygenase designed by directed evolution. Patent no. P300212672.

(33) Alcalde, M. Mutagenesis Protocols in Saccharomyces cerevisiae. In Vivo Overlap Extension In: In vitro Mutagenesis Protocols, $3 r d$ ed. Methods in Molecular Biology; Bramman, J., Ed.; Springer-Humana Press: New York, 2010; pp 3-15.

(34) Kille, S.; Acevedo-Rocha, C. G.; Parra, L. P.; Zhang, Z. G.; Opperman, D. J.; Reetz, M. T.; Acevedo, J. P. Reducing codon redundancy and screening effort of combinatorial protein libraries created by saturation mutagenesis. ACS Synth. Biol. 2013, 2, 83-92.

(35) Sastry, G. M.; Adzhigirey, M.; Day, T.; Annabhimoju, R.; Sherman, W. Protein and ligand preparation: parameters, protocols, and influence on virtual screening enrichments. J. Comput.-Aided Mol. Des. 2013, 27, 221-234.

(36) Anandakrishnan, R.; Aguilar, B.; Onufriev, A. V. H++ 3.0: automating $\mathrm{pK}$ prediction and the preparation of biomolecular 
structures for atomistic molecular modeling and simulations. Nucleic Acids Res. 2012, 40, W537-W541.

(37) Desmond Molecular Dynamics System, version 2.2; D.E. Shaw Research, New York, NY, 2009. Maestro-Desmond Interoperability

Tools, version 2.2; Schrödinger: New York.

(38) QSite, version 5.7; Schödinger, LLC: New York, 2011.

(39) Jaguar, version 8.1; Schrödinger, LLC: New York, 2013. 